\title{
An Experimental Study on Burning of Vertical Cloth Panels
}

\author{
AKANKSHA MATHUR ${ }^{1}$, D. HARSHA VIKAS ${ }^{2}$, and SUNIL R. KALE ${ }^{1}$ \\ ${ }^{1}$ Department of Mechanical Engineering \\ Indian Institute of Technology Delhi \\ New Delhi 110016, India \\ ${ }^{2}$ Department of Mechanical Engineering \\ National Institute of Technology \\ Warangal 506004, India
}

\begin{abstract}
In many countries, tents are used for public gatherings. In India they are known as shamiana and are custom-made and assembled and disassembled on site in a short time. The structure consists of a metal or wood frame that is covered by fabric panels to produce a closed, open or semi-open structure. Fires in these structures are frequent and spread rapidly resulting in considerable loss of life. In this study, vertical panels of fabrics used in typical shamiana construction were tested for burning characteristics with a nichrome wire ignition as ignition source placed at two locations, viz., bottom center or top center. The process was video taped; individual images were analyzed for flame and char parameters. Bottom ignition of cotton panel results in rapid vertical spread whereas with top ignition the burning process is much slower with vertical burning velocities being 9.0 and $0.2 \mathrm{~cm} / \mathrm{s}$, respectively; the horizontal burning velocities were similar at $1.1 \mathrm{~cm} / \mathrm{s}$ for both. With bottom ignition, polyester burning results in a regular fall of burning globules to the ground and the spread rate is $2.0 \mathrm{~cm} / \mathrm{s}$ and $1.0 \mathrm{~cm} / \mathrm{s}$ in vertical and horizontal directions, respectively. With top ignition, the burning rate is $1.6 \mathrm{~cm} / \mathrm{s}$ in vertical direction and $1.8 \mathrm{~cm} / \mathrm{s}$ in horizontal direction. With bottom ignition, the vertical and horizontal flame accelerations are 0.4 and $0.3 \mathrm{~cm} / \mathrm{s}^{2}$, respectively. For polyester, the vertical accelerations are much smaller $\left(0.05 \mathrm{~cm} / \mathrm{s}^{2}\right)$ during the initial part followed by a very small deceleration.
\end{abstract}

KEYWORDS: flame spread, fabric, shamiana.

\section{INTRODUCTION}

In India, and many other countries, social gatherings, such as, marriages, parties, get-togethers and fairs, are held in improvised structures known as a shamiana, Fig. 1. A shamiana has a steel or wooden frame structure which is covered with cloth (fabric) panels that are tied to the frame at the cloth edges. The enclosure so formed can be open, semi-open or fully enclosed. The interiors include carpets, furniture, decorative materials. Power to lights, fans and music systems is via electric wiring laid on the structure. The basic unit of such a structure is a cell, $4.5 \times 4.5 \times 3.6 \mathrm{~m}$ high and several cells assembled adjacent to one another make a large enclosure such as in Fig. 1. A shamiana is custom made on site and can be designed to accommodate up to 2,000 people. The fabrics are cotton, polyester, dosuti (double layered cotton), georgette, satin and lycra. Fabrics for carpets are jute and polyester, foams for mattresses and cushions. Decorative materials are made of wood, thermocole, foam, nylon ropes and PVC sheets. Ignition sources could be sparking in electrical connections, falling crackers or exposed flames inside the shamiana (for religious ceremonies). The above materials are flammable, and when ignited at one point, the fire spreads rapidly to adjacent panels and to the floors resulting in a swift collapse of the fabric panels. Such fires occur frequently and have resulted in considerable fatalities (Dabwali, 1995: 446 fatalities; Meerut, 2006: 60 fatalities; Jamshedpur, 1989: 60 fatalities). Regulatory systems are minimal and often not followed. A scientific study of such fires has not been undertaken and this paper is a step in this direction. In this study, the fabrics used in shamianas have been characterized; small vertical panels were ignited and their burning has been studied.

Standards, e.g. ISO 6941:2003 [1] and ASTM D1230-94 [2] describe the methods for the measurement of flame spread of vertically oriented fabrics in vertical orientation with bottom ignition. The sample is small in size and, when a backing plate is provided, it is not representative of shamianas and tents. 


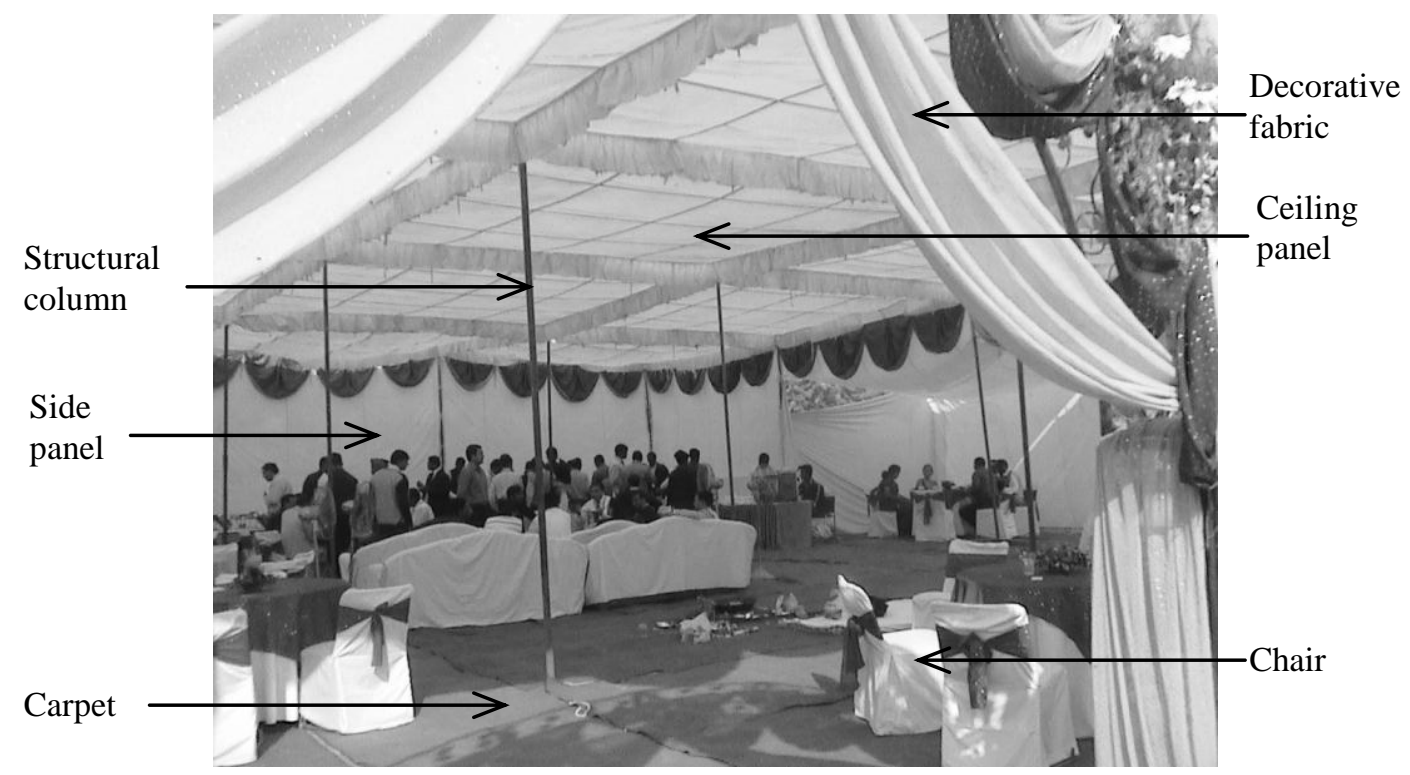

Fig. 1. Photograph of a shamiana.

Studies on fabric strips [3] have contributed to the development of standardized test procedures. Experimental studies [4] indicated trends for flame spread of modern textiles and the fabric characterization. The experiments were on a small scale NFPA 701 (1989) test with vertical panels and bottom ignition. Unlike a point ignition, the effect of a line ignition of the bottom edge of a vertical fabric panel [5] showed that two-dimensional upward flame spread over cotton fabrics remains laminar for a short initial period after which the flames become turbulent. Mass burning rates and mass heating rates were found to be independent of angle, relative humidity, or fabric mass per unit area, and remained constant over a major part of the flame spreading process. The flame spreading process was accelerating as long as a two-dimensional structure was preserved. The results from these small sample tests are of limited use in understanding the fire safety of a shamiana where panels are larger, are oriented vertically or horizontally and ignition could be at the top or at the bottom.

In a series of experiments to understand fire propagation in a tent camp, a logarithmic relation was observed between the burning time of a tent and air speed and the density of tent fabrics [6]. For predicting burn injuries, the flame spread of fabrics draped on a manikin were studied experimentally $[7,8]$ for different types of fabrics whose characteristics were documented. These studies, while providing valuable information on the fire safety, are not adequate for an understanding of the thermal hydraulics of shamiana type enclosure fire that disintegrates rapidly during the burning process.

\section{EXPERIMENTAL SET-UP AND PROCEDURE}

\section{Experimental Set-up}

The test chamber was designed to accommodate a sample large enough to obtain data on flame spread in top and bottom ignition. Since fires are very sensitive to mild drafts, a semi-enclosed chamber was designed, Fig. 2a. Further, to minimize wall effects, the guideline in ISO-6941 which specifies that the test cloth sample should be kept at least $0.30 \mathrm{~m}$ from the nearest wall was followed. The overall dimensions of the chamber (Fig. 2) are $1.5 \mathrm{~m} \times 1.5 \mathrm{~m} \times 3.0 \mathrm{~m}$ high. A steel frame was constructed and the bottom $0.3 \mathrm{~m}$ and the top $0.9 \mathrm{~m}$ were covered with a wire mesh for ventilation. The remaining height was closed on two sides with a wood panel, on one side with a door and on the front by a Perspex sheet for visual access. The chamber was placed in the open where ambient current could influence the burning. The chamber design isolates ambient air movement while maintaining the upper limit of $0.2 \mathrm{~m} / \mathrm{s}$ of air movement in the vicinity of sample as required in ISO 6941. This compliance with the upper limit of air velocity was established by smoke visualization inside the enclosure under still outside conditions. 
Figure $2 \mathrm{~b}$ shows the fabric mounting arrangement which is a steel frame of adjustable height and width. The cloth was clamped on its sides between two steel sections over its entire height. The maximum dimensions that can be accommodated are $1.2 \mathrm{~m} \times 1 \mathrm{~m}$. The device rests on the floor with a steel base frame. Based on the above, the clear dimensions of the fabric panel were $0.49 \mathrm{~m}$ wide and $0.84 \mathrm{~m} \mathrm{high}$; the cut width was greater for clamping on the sides.

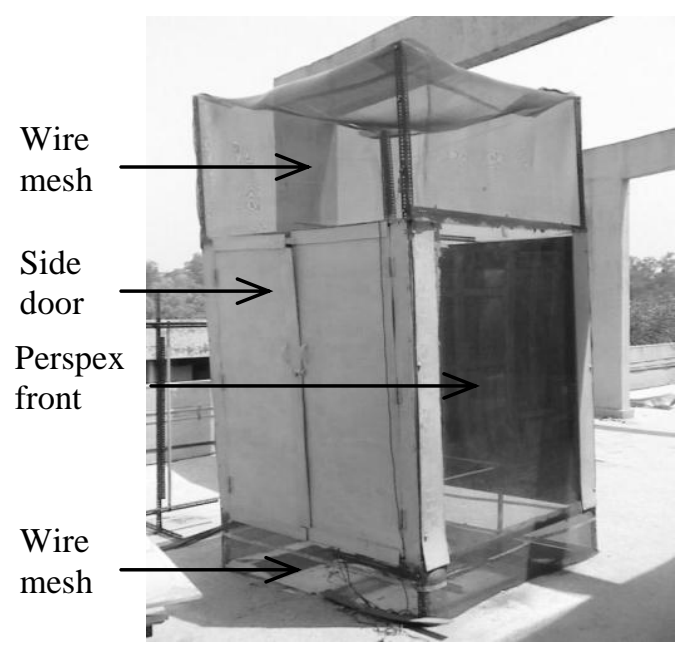

(a)

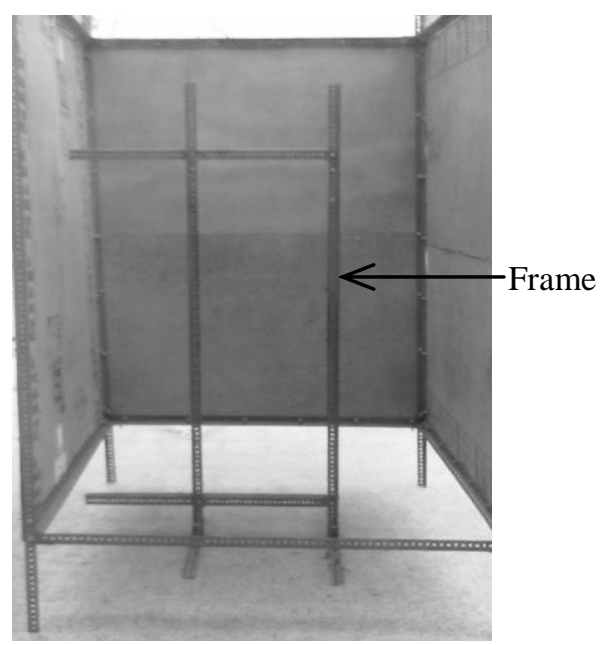

(b)

Fig. 2. Photograph of the test chamber: (a) outside view; (b) interior and mounting device.

A point source of ignition was used because electric sparking is a major initiator of fires in shamianas. The igniter was a nichrome wire $0.5 \mathrm{~mm}$ diameter made into a cylindrical coil of $3 \mathrm{~mm}$ diameter and $6 \mathrm{~mm}$ length. It was powered through a variac and the repeatability was established by ensuring that (a) the cloth sample was ignited at the same voltage, (b) proper contact between sample and nichrome wire was made by holding the ignition location of cloth sample inside the cylindrical loop of the wire, (c) power was supplied for a duration of 5-8 s, and (d) maintaining the dimensions of the coil.

The burning process was video recorded with a handy-cam (Sony, Model: DCR-SR30). The camera was mounted on a tripod and placed normally at the centre of the panel as viewed from the front. The image was calibrated by placing panels of known size at the distance at which the cloth would be placed.

\section{Experimental Procedure}

The fabric sample $(0.60 \mathrm{~m}$ wide and $0.84 \mathrm{~m}$ high) was cut from a large piece of which $55 \mathrm{~mm}$ on each longer side was used in clamping; the test size was $0.49 \mathrm{~m}$ wide and $0.84 \mathrm{~m}$ in height. The bottom edge was $0.45 \mathrm{~m}$ above the floor. The experiments were performed at night or dusk; this enabled clear recording of the luminous flame and avoided reflections due to the Perspex front. After mounting the cloth sample, the frame was placed in the chamber and the ignition wire was attached. Following this, the door was closed and the camera switched on for recording. The sample was ignited and the entire burn sequence was videotaped.

The software packages for image analysis were Video to JPG converter 1.4.2.1 for cropping the video (MPG format) and converting the cropped video into JPG snapshot files. This processing was done at regular intervals of 0.5-5.0 s depending upon the rate at which the fabric was burning. ImageJ software with a separate code was used to crop the JPG files into a desired size for input for image analysis. For image analysis, MATLAB 7.4.0 (R2007) $a$ was used. The analysis started with converting the cropped images into colour (RGB) scale and then into gray scale. Figure 3a shows a digitalized and cropped/sized image from the video file, and Fig. $3 \mathrm{~b}$ shows the same picture in gray scale. From this gray scale picture, the no flame background was subtracted and using this output, the flame and char edges were detected by a function written for edge detection, Figs. $3 \mathrm{c}$ and $3 \mathrm{~d}$. The detection function used the Canny method (in MATLAB) which detects the edges by looking for local maxima of the gradient of the binary image. The gradient is calculated using the derivative of a Gaussian filter. The method uses two thresholds, to detect strong and weak edges, and includes the weak edges in the output only if they are connected to strong 
edges. The thresholds for this purpose were arrived at by processing the image with different pairs of high and low values of the thresholds, and the values that yielded the best continuous composed edge of the flame with minimum noise was taken as the set input values in the Canny method for a particular sequence. This method was used because it is less likely to be affected by noise as compared to other methods and, therefore, more likely to detect true edges. The pixels from this detection were calibrated to give physical dimensions of flame and char parameters in the main code. For cotton with bottom ignition, several variations of the algorithm for image analysis were carried out for obtaining the flame tip distance $\left(y_{f}\right)$ from the bottom edge of the fabric panel, maximum flame width $\left(x_{f}\right)$ along the width of panel; char tip distance $\left(y_{c}\right)$ along the direction of flame spread and char spread, $\left(x_{c}\right)$. The char area was approximated as a triangle in case of cotton. Different codes have been written for evaluating flame propagation and char area (in case of cotton fabric) separately. Similarly, parameters for polyester and cotton top ignition were evaluated using different algorithms. The uncertainty in these data would arise from the threshold values applied for detecting strong and weak edges. From the pixel data, the uncertainty in the height and width is about $\pm 1 \%$ which results in a similar uncertainty in the corresponding speeds and $\pm 1.4 \%$ in area. For any sequence, generally two pairs of thresholds had to be employed to filter out the noise caused by the reflections from the cloth which developed wrinkles as the burning progressed. This procedure would, therefore, produce consistent data.

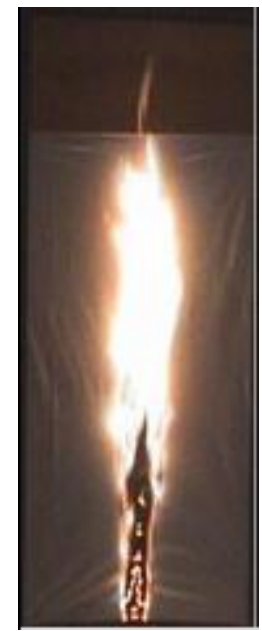

(a)

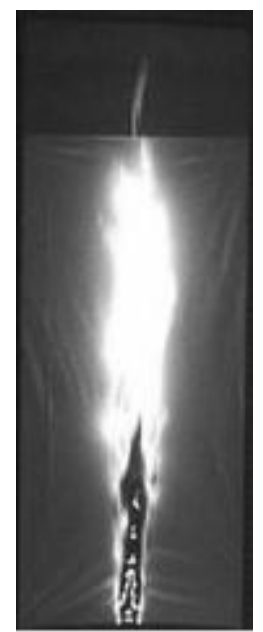

(b)

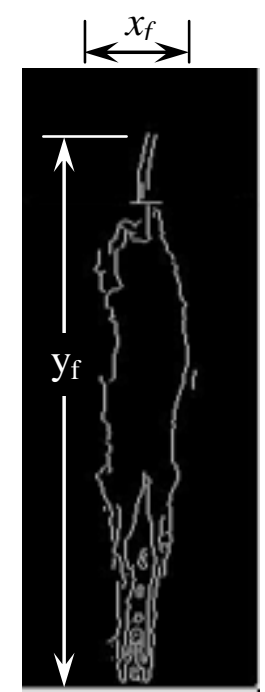

(c)

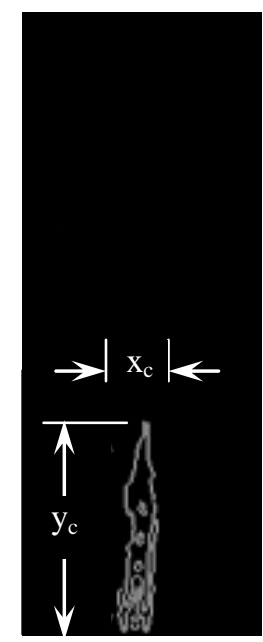

(d)

Fig. 3. Image processing technique: (a) sized; (b) gray scaled; (c) flame edge detected; (d) char edge detected.

Prior to the experiments, circulation in the chamber was studied by smoke visualization to confirm low air velocities and effects of ambient air currents. Strong air currents around the chamber were affecting the flow inside the chamber and, hence, all experiments were conducted when ambient air was still. Four sets of configurations were experimented, viz., cotton and polyester fabric, each with bottom center and top center ignition. Each configuration was repeated three times, from which repeatability was assessed.

\section{RESULTS FOR COTTON PANELS}

\section{Cotton Bottom Center Ignition}

Figure 4 shows images at different times for cotton fabric ignited at the bottom centre. The ignition delay, i.e. time from energizing the current to appearance of the flame, was about 2-3 s. The zero for the time corresponds to the first appearance of the flame. Figure 4a shows the first appearance of the flame on the edge. The flame grows into a composed flame after about $3 \mathrm{~s}$, Fig. $4 \mathrm{~b}$. This flame grows and becomes turbulent after $8 \mathrm{~s}$, Fig. $4 \mathrm{c}$ where post-combustion char formation is visible. The char breaks up vertically and smolders at the edges. By $10 \mathrm{~s}$, the flame has increased in size and its tip is above the vertical edge of the cloth, Fig. 4d. The flame accelerates and grows, Fig. 4e and at 19 s, Fig. $4 \mathrm{f}$ the char length is over the 
entire height of the fabric. Just after about $19 \mathrm{~s}$, the cloth breaks-up and folds around the vertical support at its edges. The two broken parts then burn separately as a layered (partially wrapped) fabric. The flame propagation for the vertical panel is, therefore, considered until $19 \mathrm{~s}$, although from a fire safety perspective, the subsequent process is also very important as it initiates combustion at adjacent cells.

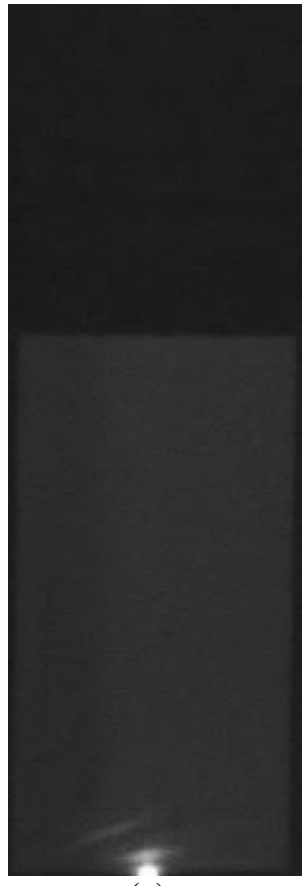

(a)

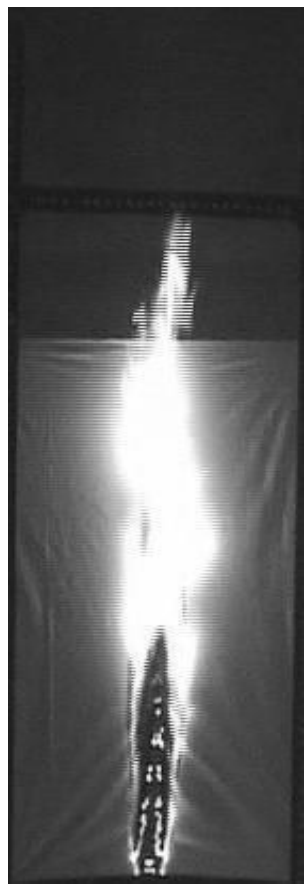

(d)

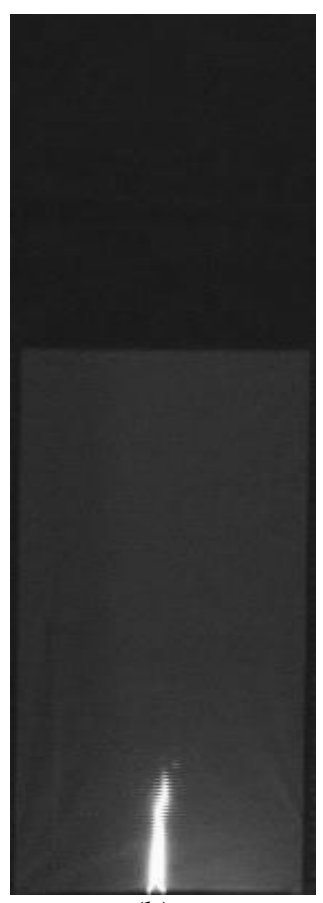

(b)

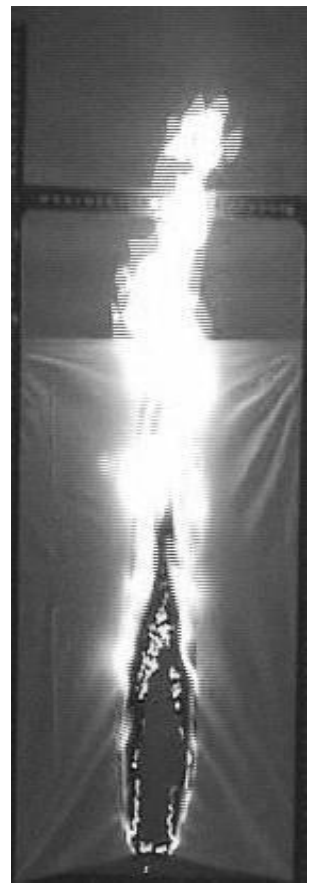

(e)

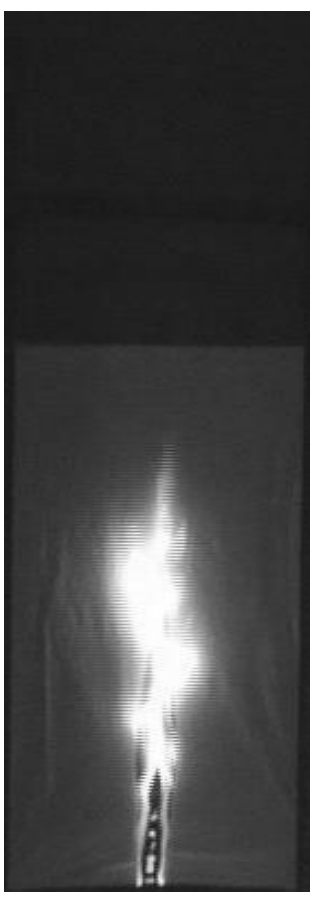

(c)

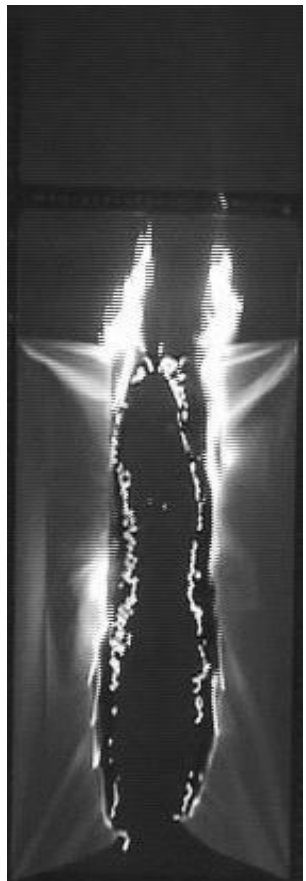

(f)

Fig. 4. Time sequence of the burning of cotton fabric with bottom centre ignition: (a) $0.5 \mathrm{~s}$; (b) $3 \mathrm{~s}$; (c) $8 \mathrm{~s}$; (d) $10 \mathrm{~s}$; (e) $13 \mathrm{~s}$; (f) $19 \mathrm{~s}$. 
The image analysis data are shown in Fig. 5. The time variations of flame tip distance from the bottom edge and maximum flame width (normalized on the fabric height and width, respectively) are shown in Fig. 5a. The highest point attained by the flame tip from the source of ignition was nearly $1.29 \mathrm{~m}$ which is almost $53 \%$ greater than the height of the cloth. This condition occurs at $15 \mathrm{~s}$ which is $4 \mathrm{~s}$ before the break-up. The vertical flame speed initially (at $0-4 \mathrm{~s}$ ) is about $4.3 \mathrm{~cm} / \mathrm{s}$, then increases to about $10.8 \mathrm{~cm} / \mathrm{s}$ (at 4-12 s). The flame speed accelerates at a rate of $0.4 \mathrm{~cm} / \mathrm{s}^{2}$ which is as expected [9] for the vertical orientation with ignition at the bottom edge. Until about $4 \mathrm{~s}$, the flame width is very small and constant. It increases gradually and after $8 \mathrm{~s}$ grows steadily at a rate of $1.3 \mathrm{~cm} / \mathrm{s}$ during which time it is less than half the flame height. The rate of growth of flame width is $0.3 \mathrm{~cm} / \mathrm{s}^{2}$. The maximum flame width occurs just before breakoff and is about $370 \mathrm{~mm}$. This indicates that the flame width is not affected by fabric width which was $0.49 \mathrm{~m}$; this would not be the case in tests with fabric strips that are narrow.

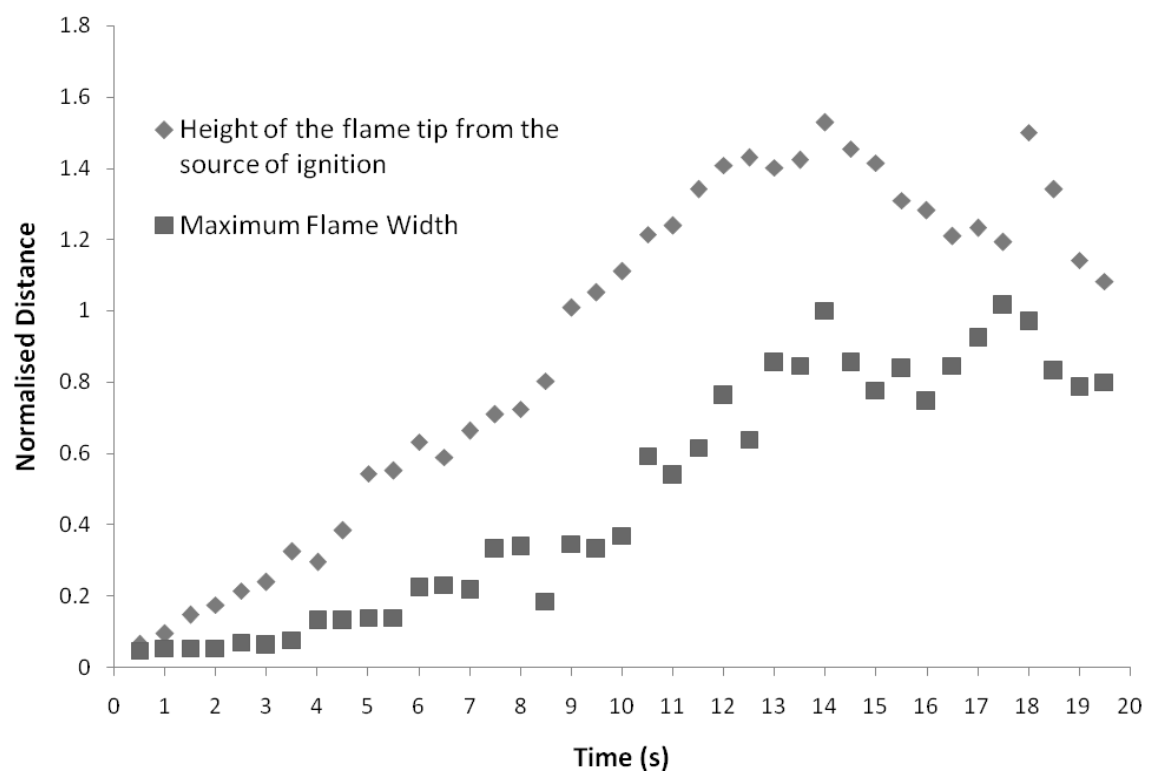

(a)

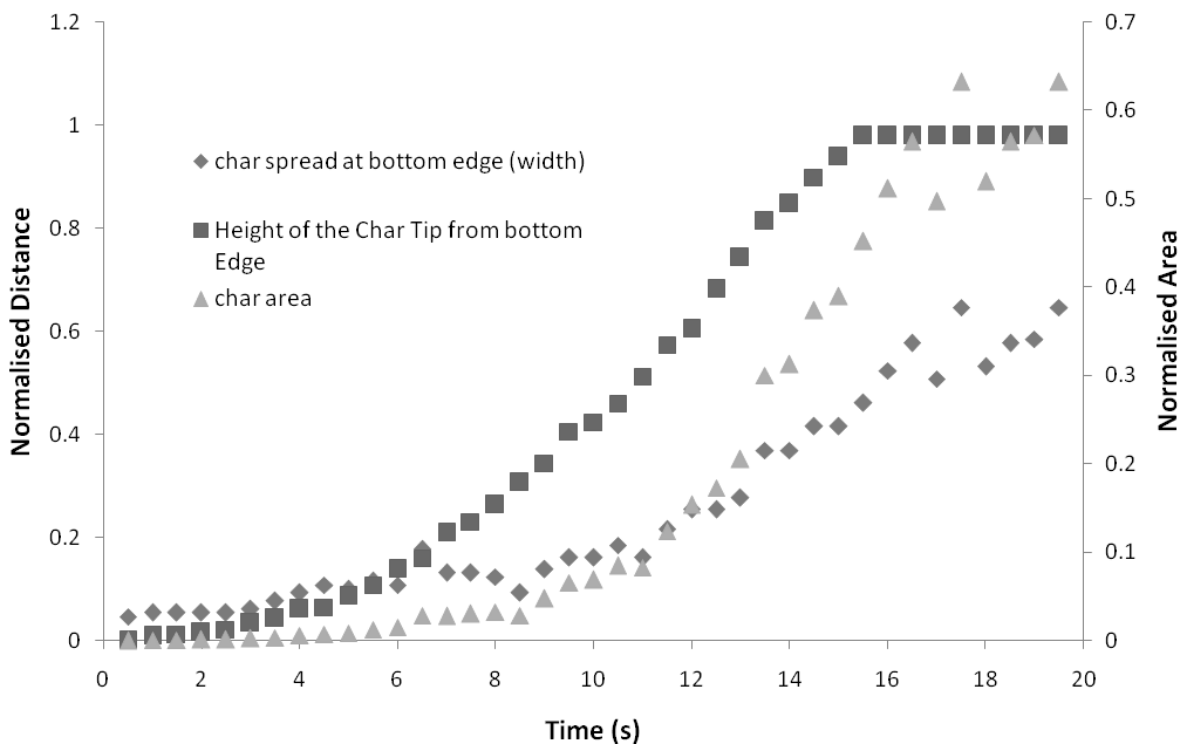

(b)

Fig. 5. Burning characteristics of cotton fabric with bottom center ignition: (a) flame characteristics; (b) char characteristics.

The char characteristics are shown in Fig. 5b. The char tip distance, width and area show a continuous increasing trend. The char height accelerates gradually until 6-8 s and then grows at a steady rate of 
$7.7 \mathrm{~cm} / \mathrm{s}$. Just before $16 \mathrm{~s}$ the char region touches the top edge of the fabric. However, the fabric does not split into two until $19 \mathrm{~s}$; this indicates that the char has some strength to keep it intact. The point where the fabric has split vertically is slightly lower than the peak of the char zone. The overall vertical char tip spreading process is an accelerating one $\left(5.4 \mathrm{~cm} / \mathrm{s}^{2}\right)$. After an initial period of slow growth, the char spread (width) increases slowly and linearly at a rate of $17.5 \mathrm{~cm} / \mathrm{s}$ until approximately $20 \mathrm{~s}$, at which point the cloth breaks up. The char width at break-up was $316 \mathrm{~mm}$ for the $490 \mathrm{~mm}$ wide sample, indicating that sample width was not a factor in char growth. The char area growth is very slow until $10 \mathrm{~s}$ after which it accelerates and increases at $138 \mathrm{~cm}^{2} / \mathrm{s}$ up to $17.5 \mathrm{~s}$.

\section{Cotton Top Center Ignition}

Figure 6 shows the images of the burning of a cotton cloth clamped vertically and ignited at center of the top edge. The striking feature was that a steady flame was never observed. After center ignition, the flame remains localized on the top edge as seen at $30 \mathrm{~s}$ in Fig. 6a. The flame travels along the edge even as the edge itself is receding after combustion; Figs. $6 \mathrm{~b}-\mathrm{f}$. Initially the cloth burns with discrete small flames that are barely visible. They gradually die at one location and reappear at another location; however, charring continues indicating that smoldering is significant. Charring spreads quickly across the width relative to its downward spread until it reaches the vertical frame edges. As charring grows vertically, its mass increases and it breaks off. The sequence also shows that there is predominant directional spread

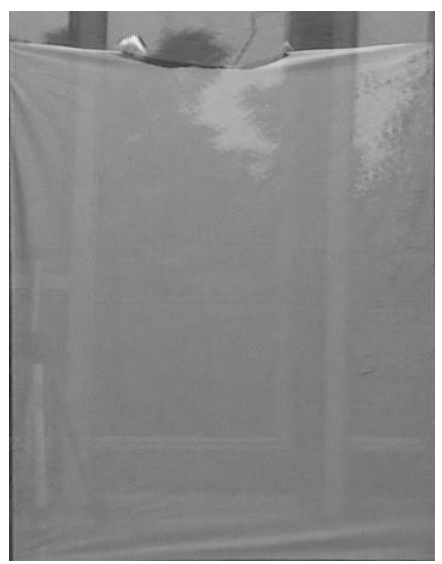

(a)

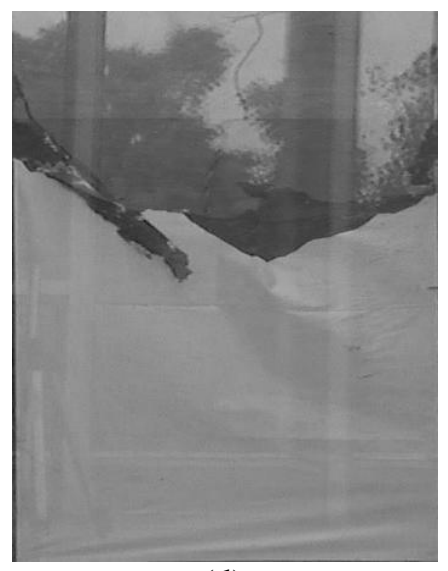

(d)

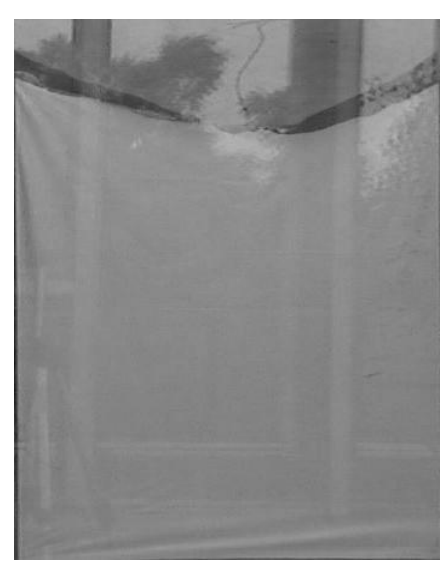

(b)

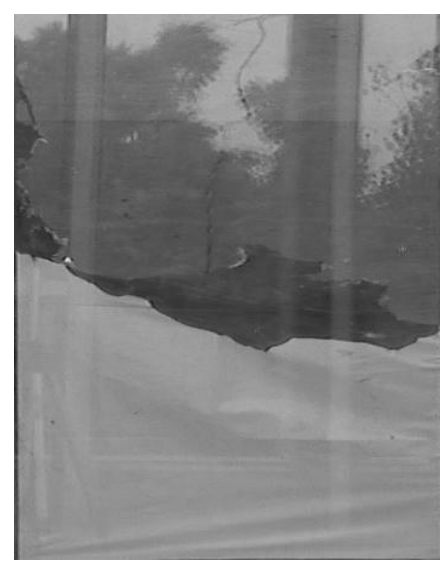

(e)

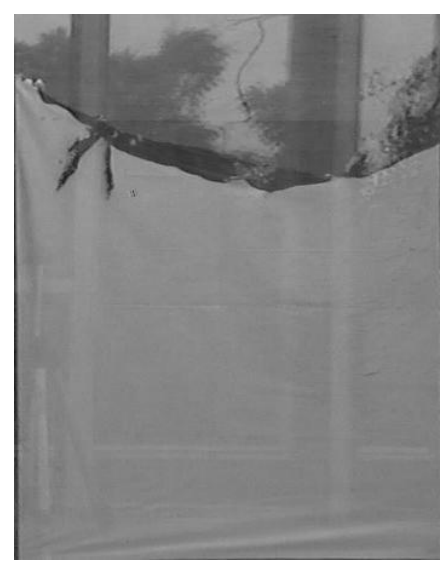

(c)

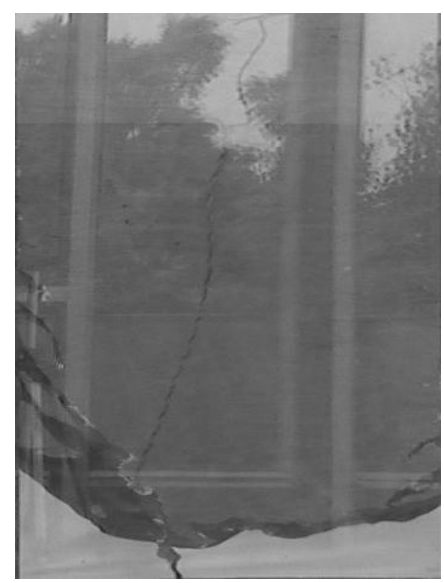

(f)

Fig. 6. Time sequence of the burning of cotton fabric with top center ignition: (a) $30 \mathrm{~s}$; (b) $45 \mathrm{~s}$; (c) $120 \mathrm{~s}$; (d) $180 \mathrm{~s}$; (e) $240 \mathrm{~s}$; (f) $370 \mathrm{~s}$. 
either horizontally or vertically; however, the spread at the center was slightly faster than that at the sides. The cloth broke up after $400 \mathrm{~s}$ when the char/flame reached the bottom edge, by which time a significant amount of the fabric had been burnt.

The burning seen in Fig. 6 shows absence of a well established flame and, therefore, flame characteristics are not presented. The char characteristics are shown in Fig. 7. The char width grows rapidly and reaches both edges $50 \mathrm{~s}$ after ignition. Subsequently, the entire width has char of varying depths as the burning proceeds downwards. The downward spread rate is almost steady at $0.2 \mathrm{~cm} / \mathrm{s}$ over the entire process, much slower and almost constant until the bottom edge is charred. The rate of change of char area is steady with time and almost linear, after $60 \mathrm{~s}$ which is the time taken to reach the edges. No acceleration is seen in this process. The average horizontal spread rate of char is faster than the downward spread by nearly 5 times.

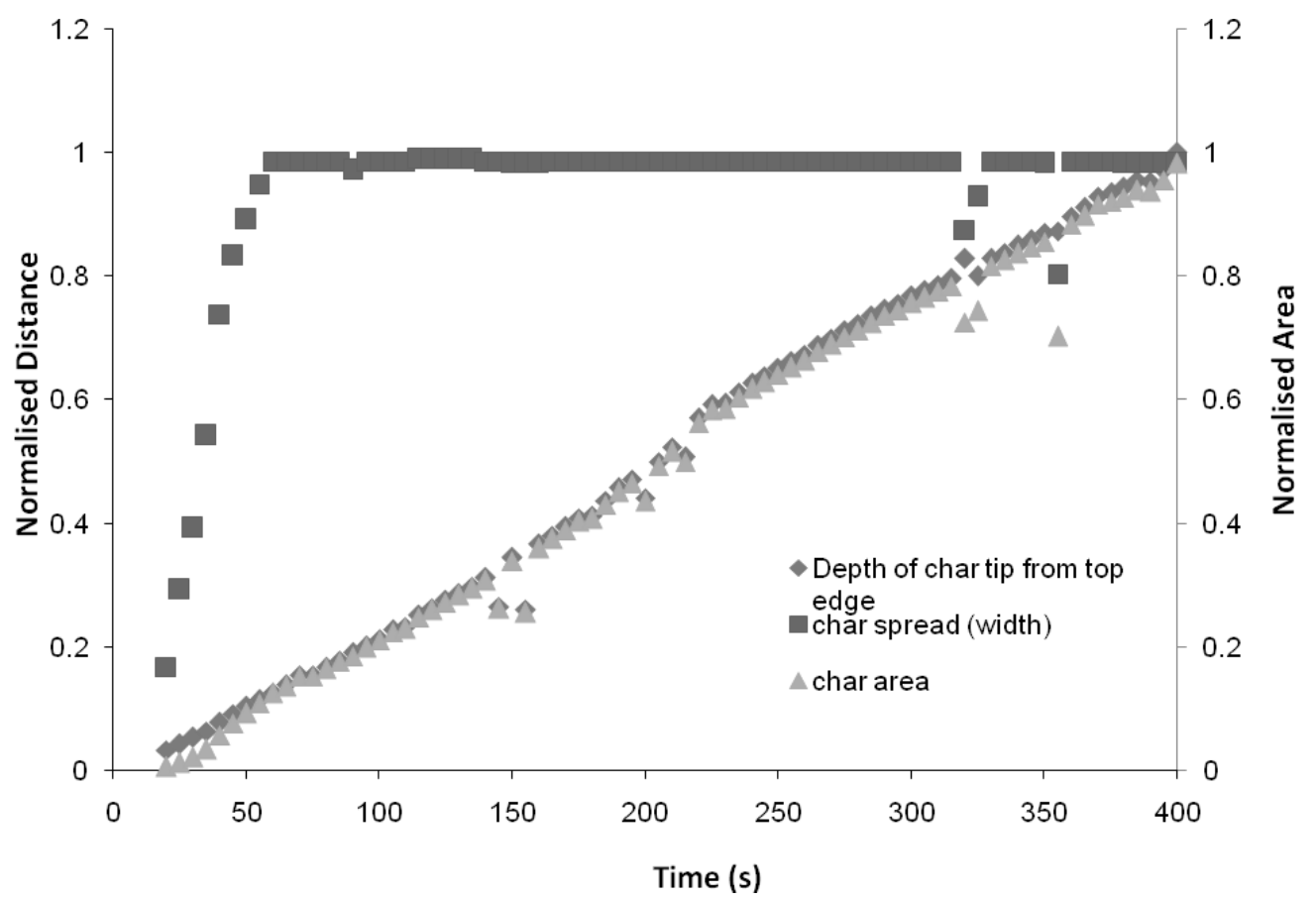

Fig. 7. Char characteristics of cotton fabric burning with top center ignition.

\section{RESULTS FOR POLYESTER PANELS}

\section{Polyester Bottom Center Ignition}

Figure 8 shows pictures of a vertical polyester panel burning after bottom centre ignition. A delay of about $6 \mathrm{~s}$ was observed after which a small flame appears, Fig. 8a. Initially the flame spreads slowly and is continuous as seen in Figs. 8b and 8c. After $18 \mathrm{~s}$, the continuous flame breaks up and local flames are seen, Figs. 8d-f. The flame breaks-up at different locations as it grows. The flame height is quite small. However, a small portion of the burnt fabric becomes a globule that falls down; some of these globules were burning while others were not. The burning globules continued to burn on the floor for a considerable time. There is no char formation during the process. The flame front predominantly grows upwards up to the top edge, Figs. 8d-f; it reaches the top edge before it reaches the side edges. The cloth broke-up after $37 \mathrm{~s}$.

Since no persistent composed flame was observed, flame parameters have not been computed. Similarly, char characteristics cannot be studied since charring was not observed. The burnt portion characteristics are shown in Fig. 9. The burnt cloth height grows for $10 \mathrm{~s}$ in an accelerating mode and then at a nearly steady rate until $25 \mathrm{~s}$ after which it shows a decelerating trend. The steady state burning rate is $2 \mathrm{~cm} / \mathrm{s}$, and the acceleration (until $10 \mathrm{~s}$ ) and deceleration (from $25 \mathrm{~s}$ until break-up) are $0.05 \mathrm{~cm} / \mathrm{s}^{2}$ and $-0.01 \mathrm{~cm} / \mathrm{s}^{2}$ respectively. The burnt width grows slowly until $5 \mathrm{~s}$ and then shows a sudden jump after which there is a near steady trend of $0.86 \mathrm{~cm} / \mathrm{s}$. The scatter reflects the discontinuous nature of the flame spread. The burnt 
area, which includes fabric that has burnt as well as molten globules that have fallen to the floor, shows slow growth until $5 \mathrm{~s}$ followed by an accelerating trend. The overall average rate of burning is $49 \mathrm{~cm}^{2} / \mathrm{s}$, which is directly proportional to the mass loss.

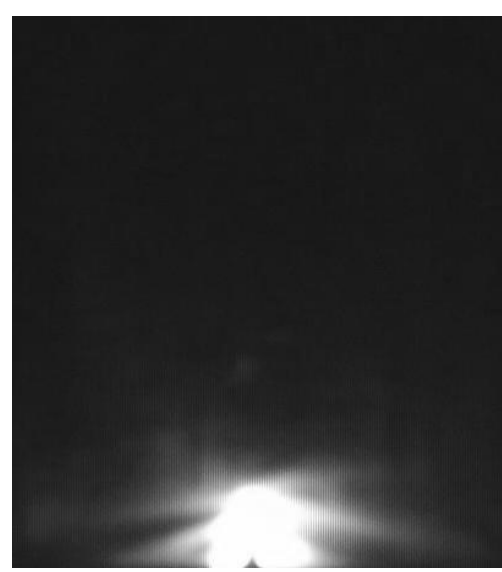

(a)

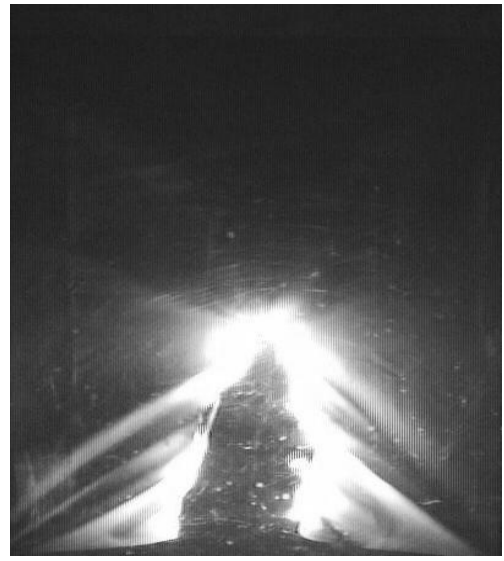

(c)

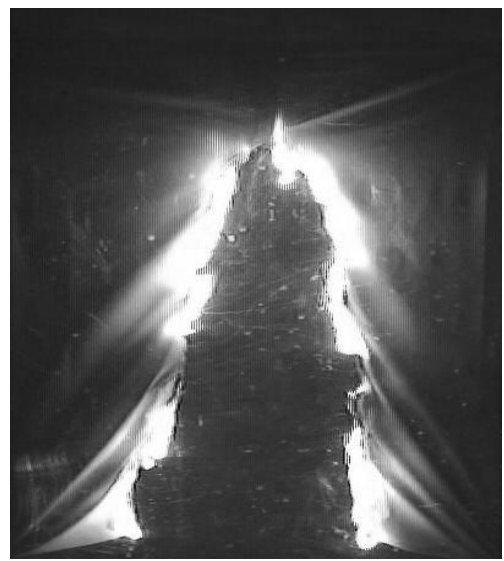

(e)

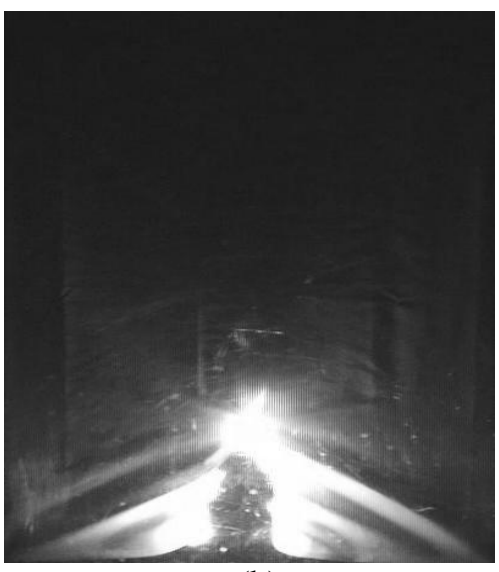

(b)

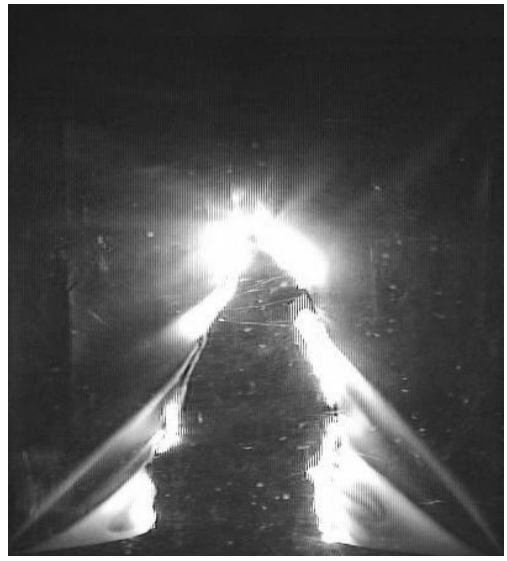

(d)

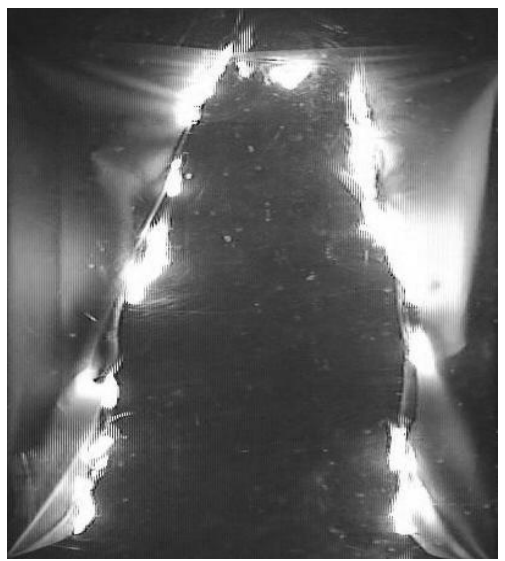

(f)

Fig. 8. Time sequence of the burning of polyester fabric with bottom center ignition: (a) $5 \mathrm{~s}$; (b) $10 \mathrm{~s}$; (c) $18 \mathrm{~s}$; (d) $23 \mathrm{~s}$; (e) $30 \mathrm{~s}$; (f) $36 \mathrm{~s}$. 


\section{Polyester Top Center Ignition}

The time sequence of burning with ignition at the center of the top edge is shown in Fig. 10. For the first $9 \mathrm{~s}$, the flame is localized, Figs. 10a-b, which then becomes disjointed and increases in size, Fig. 10c. The flames spread laterally and the entire top edge is on fire, Fig. 10d. With the entire top edge on fire, the flames spread downwards towards the bottom edge, Figs. 10e and 10f. The fabric clamped at the edges does not fall off but continuously keeps burning even after the flame has progressed below it. During the entire process, globules, some on fire, were regularly falling to the ground. The small flame in the center in Fig. 10 is the result of polyester melt adhering to the ignition wire and burning. The entire process up to break-up at the bottom edge was completed in $56 \mathrm{~s}$ and there was no char formation.

Due to the distributed and non-established flame, flame and char parameters could not be analyzed. The extent of cloth burning is presented in Fig. 11. The burnt width grows steadily to cover the sample width to about $25 \mathrm{~s}$, after which the flame extends from one side support to the other along the fabric edge; at this time the vertical distance burned was $25 \%$ of height. The burnt distance from top edge grows in an accelerated manner. The rate of change of burnt depth from the top edge accelerates at $0.05 \mathrm{~cm} / \mathrm{s}^{2}$ up to $23 \mathrm{~s}$, at which time it reaches the edge supports and then decelerates. The burnt area variation with time closely follows the burnt depth variation, and after $15 \mathrm{~s}$ it averages $1.5 \mathrm{~cm}^{2} / \mathrm{s}^{2}$.

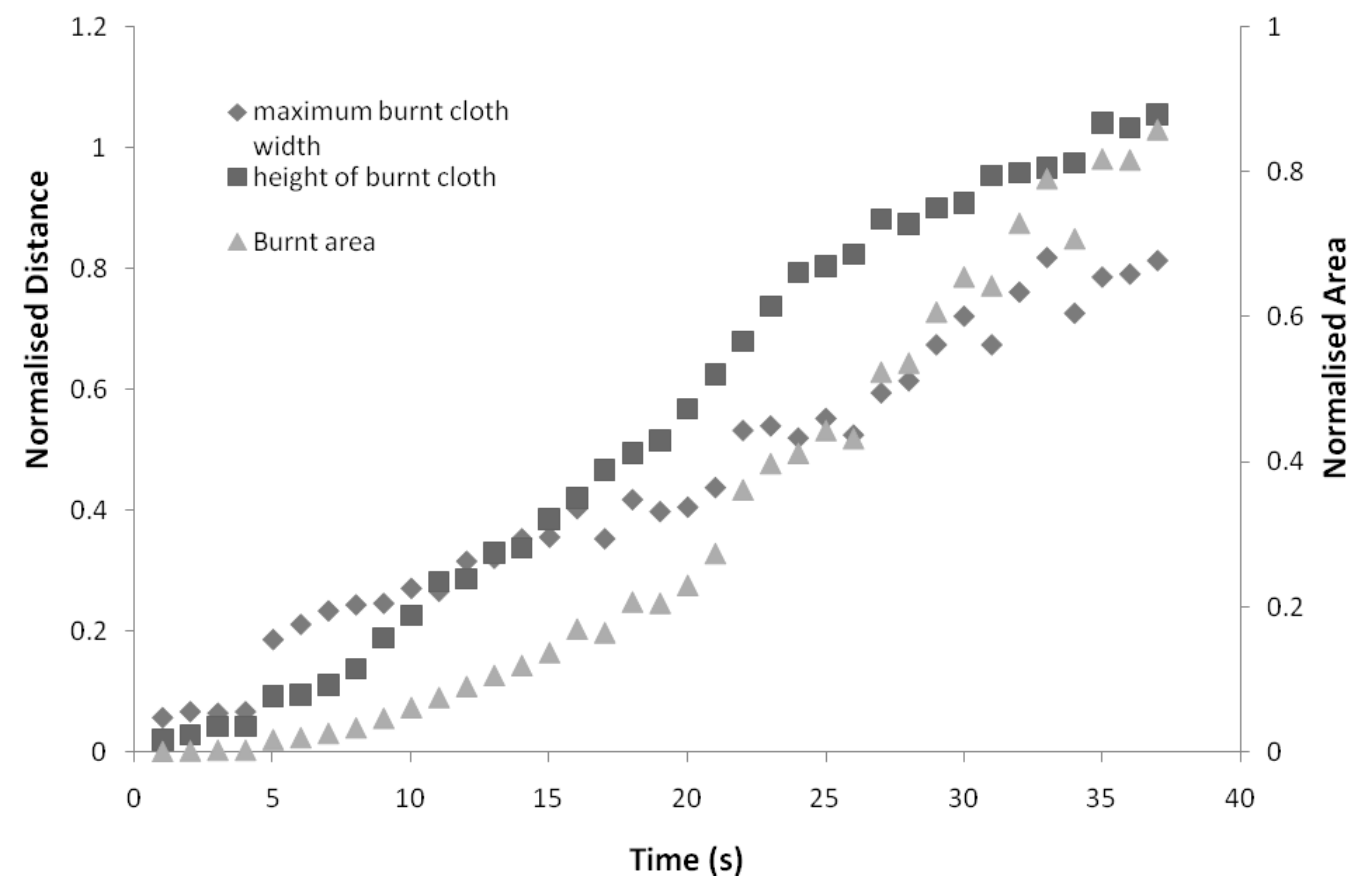

Fig. 9. Char characteristics of polyester fabric burning with bottom center ignition.

\section{DISCUSSION}

\section{Effects of Ignition Location}

A summary of burning speeds is given in Table 1; in each case the results are from three tests and the values are the mean with standard deviation given in brackets. For cotton with top and bottom ignition, the vertical burning speeds are 9.0 and $0.2 \mathrm{~cm} / \mathrm{s}$, respectively, and horizontal burning speeds are similar at $1.1 \mathrm{~cm} / \mathrm{s}$. The horizontal burning speed is not affected by the location of the ignition source. In contrast, the vertical burning rate is more than an order of magnitude greater with bottom ignition than with top ignition. For polyester, the vertical burning speeds with top and bottom ignition are 2.0 and $1.6 \mathrm{~cm} / \mathrm{s}$, respectively, and the corresponding horizontal burning speeds are 1.0 and $1.8 \mathrm{~cm} / \mathrm{s}$, respectively. Here, the burning speeds are of comparable magnitude and are not influenced by either the direction of burning or by the ignition location. 
Table 1. Summary of burning speeds.

\begin{tabular}{|l|l|c|c|}
\hline Fabric & Ignition location & Vertical speed $(\mathbf{c m} / \mathbf{s})$ & Horizontal speed $(\mathbf{c m} / \mathbf{s})$ \\
\hline \multirow{2}{*}{ Cotton } & Bottom edge center & $9.0(1.5)$ & $1.1(0.60)$ \\
\cline { 2 - 4 } & Top edge center & $0.2(0.0)$ & $1.1(0.25)$ \\
\hline \multirow{2}{*}{ Polyester } & Bottom edge center & $2.0(0.49)$ & $1.0(0.08)$ \\
\cline { 2 - 4 } & Top edge center & $1.6(0.13)$ & $1.8(0.34)$ \\
\hline
\end{tabular}

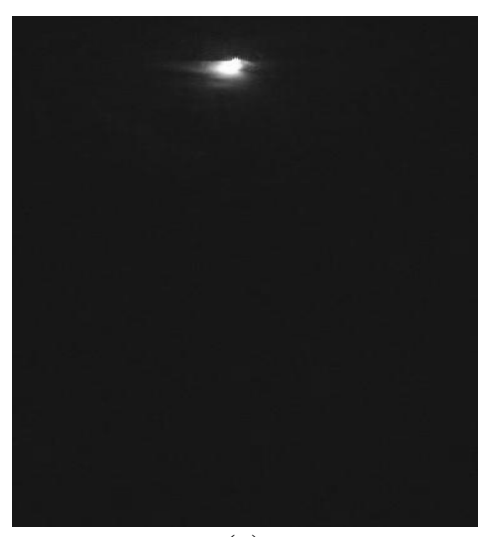

(a)

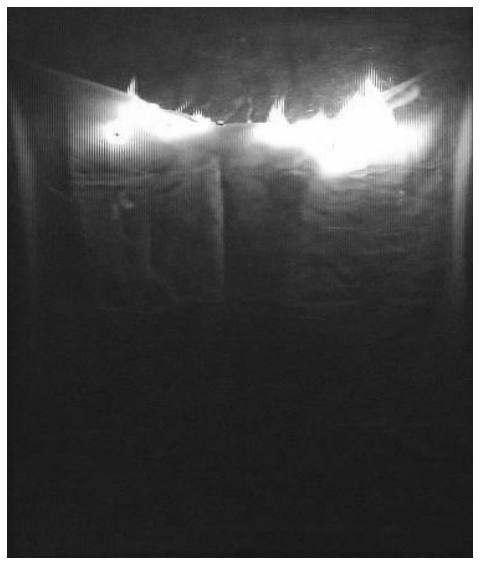

(c)

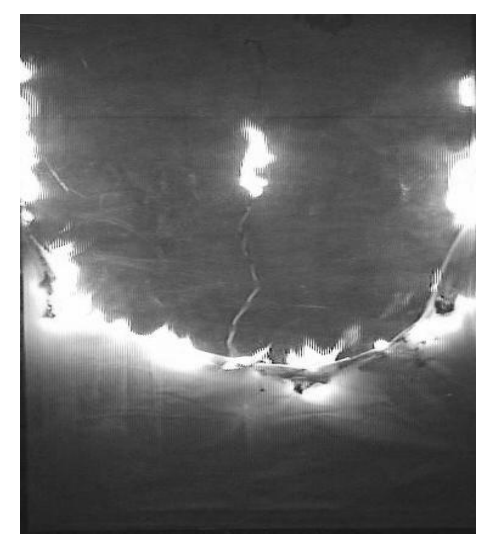

(e)

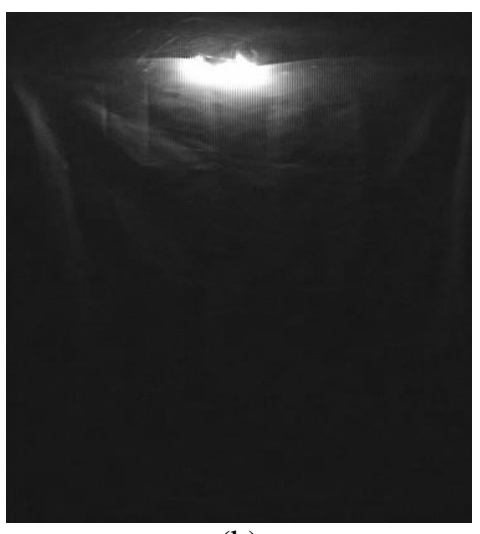

(b)

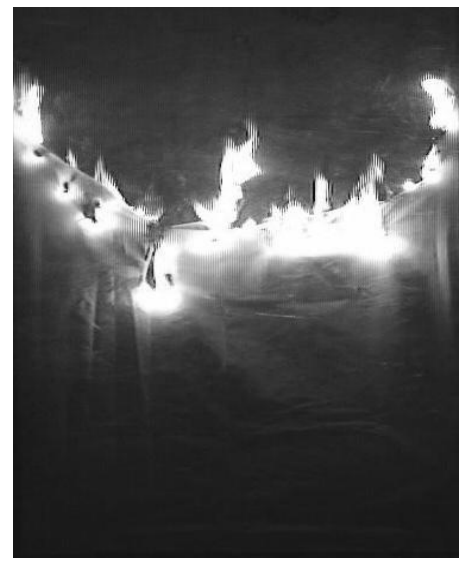

(d)

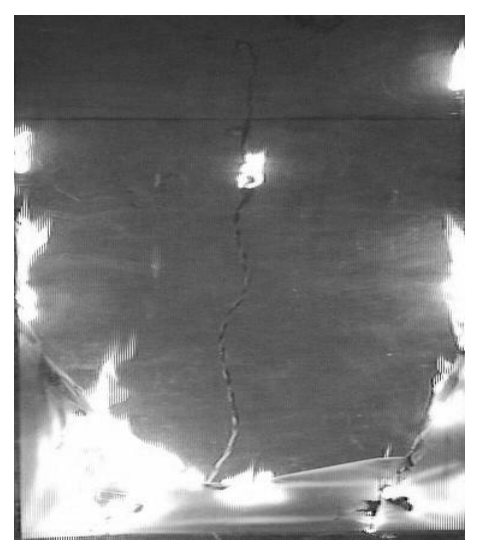

(f)

Fig. 10. Time sequence of the burning of polyester fabric with top center ignition: (a) $4 \mathrm{~s}$; (b) $9 \mathrm{~s}$; (c) $19 \mathrm{~s}$; (d) $26 \mathrm{~s}$; (e) $34 \mathrm{~s}$; (f) $56 \mathrm{~s}$. 
The flame tip distance and the maximum height that the flame reach is also different. The longest flame is seen with cotton ignited at the bottom edge, Fig. 5a. The flame tip reached a highest location that was $1.29 \mathrm{~m}$ (53\% of fabric height) above the fabric bottom edge, whereas with top ignition the flame was always small (typically $1-10 \mathrm{~cm}$ ) in height. In both configurations of polyester, the flame tip was about 1$4 \mathrm{~cm}$ above the local fabric edge.

\section{Effects of Fabric Type}

Table 1 shows that vertical burning speed for cotton with bottom ignition $(9.0 \mathrm{~cm} / \mathrm{s})$ is much greater than the corresponding value for polyester $(2.0 \mathrm{~cm} / \mathrm{s})$. With top edge ignition the trend is the opposite, i.e.

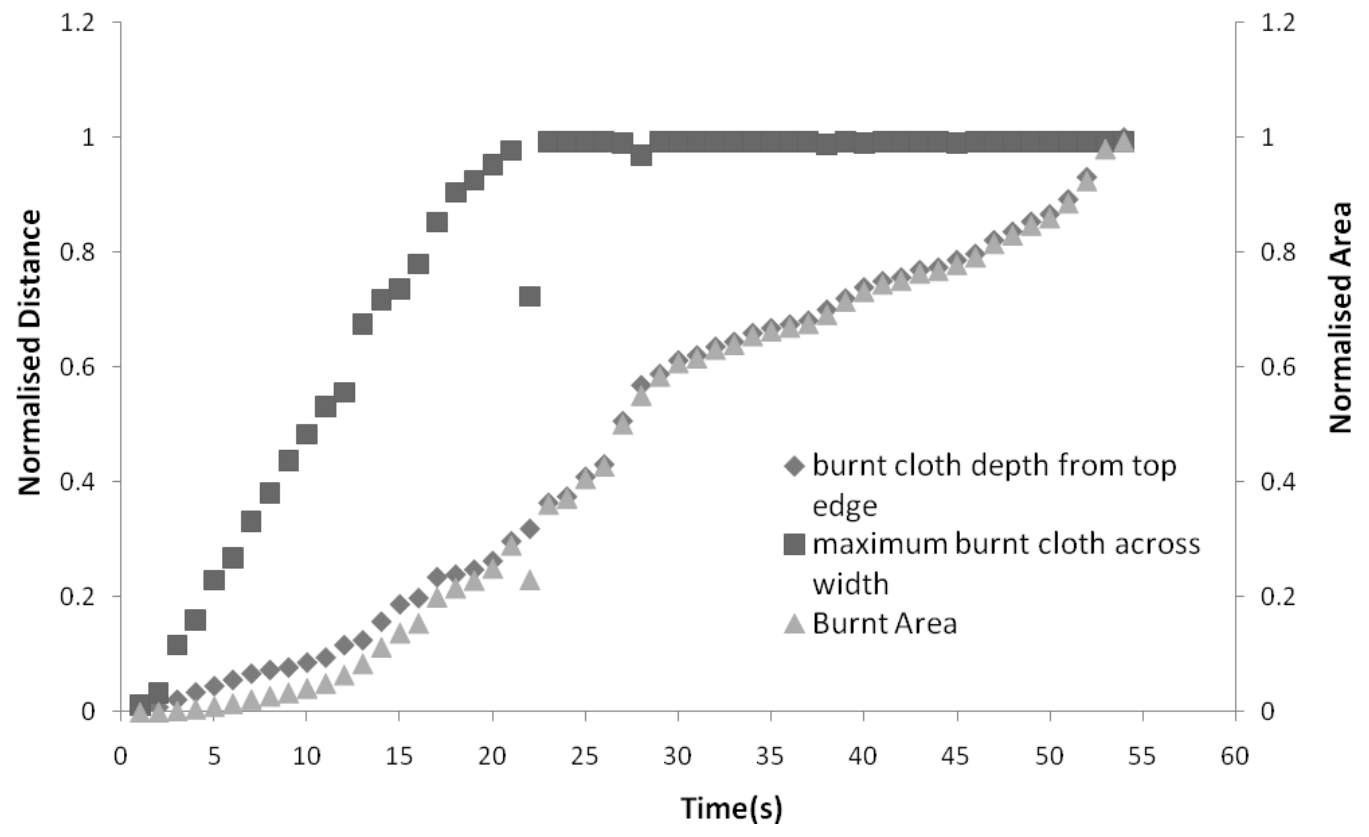

Fig. 11. Char characteristics of polyester fabric burning with top center ignition.

polyester has a burning speed of $1.6 \mathrm{~cm} / \mathrm{s}$ and cotton has $0.2 \mathrm{~cm} / \mathrm{s}$. The horizontal spread rates are weakly influenced by fabric type. The data has to be interpreted in light of the observation that polyester burning is accompanied by the formation of globules that drop off the fabric; some of these are burning and continue to burn after falling to the floor. Cotton exhibits char formation that smolders at the edges and breaks off at regular intervals, whereas there is no char formation with polyester. The fabric characteristics are given in Table 2. EPI and PPI, respectively, are number of ends and number of picks per inch. The mass per unit area $\left(\mathrm{g} / \mathrm{m}^{2}\right)$ of both fabrics is very similar. Warp, weft and cloth cover are characteristics of the weave. Both fabrics are of comparable thickness. The warp-wise and weft-wise number of fibers in the yarn $\left(N_{f}\right)$ are comparable for each fabric. The limiting oxygen index (LOI) of both fabrics is very similar and was independent of direction of ignition (top or bottom). The air permeability of cotton is much greater than that of polyester. The areas covered by yarn in the fabric $\left(A_{y}\right)$ are 63.3 and $78.2 \%$ for cotton and polyester, respectively. The fabric mass densities $\left(\rho_{f}\right)$ are comparable for both fabrics.

Table 2. Fabric characterization.

\begin{tabular}{|c|c|c|c|c|c|c|c|c|c|c|c|c|c|}
\hline \multirow[b]{2}{*}{ Fabric } & \multicolumn{2}{|c|}{ Sett } & \multirow[b]{2}{*}{$\begin{array}{c}\text { Mass/ } \\
\text { area } \\
\left(\mathrm{g} / \mathbf{m}^{2}\right)\end{array}$} & \multirow[b]{2}{*}{$\begin{array}{l}\text { Cloth } \\
\text { cover }\end{array}$} & \multicolumn{2}{|c|}{ Warp } & \multicolumn{2}{|c|}{ Weft } & \multirow[b]{2}{*}{$\begin{array}{l}\text { Thick } \\
\text { ness } \\
(\mathbf{m m})\end{array}$} & \multirow[b]{2}{*}{$\begin{array}{c}\text { LOI } \\
\text { value }\end{array}$} & \multirow{2}{*}{$\begin{array}{c}\text { Air } \\
\text { permea- } \\
\text { bility } \\
\left(\mathrm{cm}^{3} / \mathrm{cm}^{2} / \mathrm{s}\right)\end{array}$} & \multirow[b]{2}{*}{$\begin{array}{c}A_{y} \\
(\%)\end{array}$} & \multirow[b]{2}{*}{ 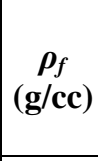 } \\
\hline & EPI & PPI & & & Count & $N_{f}$ & Count & $N_{f}$ & & & & & \\
\hline & 76 & 48 & 97.44 & 17.23 & 3 & $\begin{array}{l}80- \\
100 \\
\end{array}$ & 28 & $\begin{array}{c}100- \\
125 \\
\end{array}$ & 0.20 & 18.7 & 54 & 63.3 & 0487 \\
\hline oryester & 136 & 92 & 97.16 & 21.93 & 60 & 30 & 02 & 29 & 0.17 & 19.7 & 2.3 & 78.2 & 0.0571 \\
\hline
\end{tabular}


The detailed physical and chemical transformations that occur during the burning of cotton or polyester fabrics are not fully understood. The chemical behavior at the micro-scale has been studied but it is not adequate to explain the macro level behavior which is seen in the experiments. A brief explanation of the experimental observations based on the understanding of chemical processes of burning cotton and polyester is given below.

Cotton being a plant substance has a cellular structure whose main constituents, viz., cellulose and lignin, are made of glucosidic bonds. When heated to about 250 to $300{ }^{\circ} \mathrm{C}$, the cellulose decomposes which releases volatiles resulting in formation of thin carbonaceous char film. The edges of this char could be smoldering at the edges which quickly self-extinguishes and the film breaks-off. Polyester fabric is made of woven synthetic fiber whose yarn is the polymer polyethylene terephthalate (PET). When heated to above $260{ }^{\circ} \mathrm{C}$, it melts and flows. At higher temperatures, above $510{ }^{\circ} \mathrm{C}$, decomposition and devolatilization occur. The volatilization rates are small (compared to cotton) and, consequently, the mass burning rate is low which results in small diffusion flames. The molten fabric flows along the edge due to gravity and accumulated at another location while it is still burning. As the resultant globule grows, it breaks-off from the fabric under its own weight. Because of the flow of the residual molten material away from a location, further volatilization ceases and the flame self-extinguishes at this location, resulting in discrete intermittent flames at the fabric edge.

\section{Fire Safety Implications}

The experimental results, though for a panel of size smaller than that in actual shamianas, give insights into the fire safety of a structure made of multiple panels. The rapid flame spread speed with bottom ignition of cotton will in a short time ignite vertical and horizontal panels above it. Thus, a single fabric panel fire will rapidly become a multiple panel fire. Further, unlike conventional compartment fires where the structure constrains the fire and its ventilation, in shamianas, the fire drastically alters the ventilation. A closed structure shown in Fig. 1 will rapidly become a ventilated structure and accelerate the fire. Thus, conventional methods of predicting fires from fabric panels, such as, curtains in a room, will be unsuitable for a shamiana. Polyester fabrics, on the other hand, present a different scenario because of the burning globules that fall off. In a shamiana (Fig. 1) a burning globule falling to the floor will ignite carpets and furniture that are adjacent to the panel. Thus, in a short time, other materials in the shamiana will be on fire. In top ignition, both cotton and polyester show that the flame spreads along the edge to the side supports. The implication is that, even before the panel on fire has burned completely, the flames would have reached the side supports and the adjacent panel(s) would now be burning. An additional factor is the burning of ties that hold the fabric to the support beams and columns; as these burn off, the fabric would break and a large portion would either accelerate the burning (vertical panels) or fall on the occupants (in case of ceiling panels). In these three scenarios of fire spread, i.e. spread to top panels, to side panels and to the floor, the time required would be about a minute for the fire to spread. The implication is that in a very short period of time the fire would engulf large portions of the structure and this could be the reasons for large fatalities in shamiana fires. Fire safety regulations need to be formulated after taking these aspects into consideration.

\section{CONCLUSIONS}

The experiments have provided insights into the burning of vertical fabric panels. Cotton when ignited at the bottom burns with a well established flame that accelerates with time and reaches well above the fabric top edge, whereas top edge ignition produces a small localized flame that moves along the edge. In all conditions, polyester burning produces falling globules at regular intervals; there is almost no char structure unlike cotton. The burning speed for polyester fabric is not strongly dependent on the direction of propagation.

\section{ACKNOWLEDGEMENTS}

The fabric characterization was carried out by Mr. Pavan Manvi and his contribution is gratefully acknowledged. 


\section{REFERENCES}

[1] ISO 6941 (2003) "Textile fabrics - Burning behaviour - Measurement of flame spread properties of vertically oriented specimens," International Organization for Standardization.

[2] ASTM D1230-94 "Standard test method for flammability of apparel textiles".

[3] Mehkeri, A., and Romanowski, M., (1975) The measurement of propagation of fire in vertically suspended fabric; upward acceleration of flame front, Textile Research Journal 45(6): 500-504, http://dx.doi.org/10.1177/004051757504500611

[4] Hirschler, M.M., and Piansay, T., (2007) Survey of small scale flame spread test results of modern fabrics, Fire and Materials 31(6): 373-386, http://dx.doi.org/10.1002/fam.943

[5] Markstein, G.H., and de Ris, J., (1973) "Upward fire spread over textiles," $14^{\text {th }}$ Symposium (International) on Combustion 14:1085-1097, http://dx.doi.org/10.1016/S0082-0784(73)80098-0

[6] Abdulghani, A.A.-F., (2001) Flame propagation in a tent camp, International Journal of Energy Research 25(6): 555-561, http://dx.doi.org/10.1002/er.636

[7] Bandhu, S. and Singh, S., (1994) "Design and fabrication of a dummy for burn studies." B. Tech. project report, Mech. Engg. Dept., IIT Delhi.

[8] Rossi, R.M., Bruggmann, G. and Stampfli, R., (2005) Comparison of flame spread of textiles and burn injury prediction with a manikin, Fire and Materials 29(6): 395-406, http://dx.doi.org/10.1002/fam.904

[9] Drysdale, D., An Introduction to Fire Dynamics ( $2^{\text {nd }}$ ed.) John Wiley and Sons, Chichester, 2004, p. 241-243. 